\title{
Behavioral tests in adults: reference values and comparison between groups presenting or not central auditory processing disorder
}

Taissane Rodrigues Sanguebuche ${ }^{1}$ https://orcid.org/0000-0002-8614-8457

Bruna Pias Peixe ${ }^{1}$

https://orcid.org/0000-0003-0548-6962

Michele Vargas Garcia²

https://orcid.org/0000-0003-3779-349X

Universidade Federal de Santa Maria - UFSM, Programa de Pós-graduação (Doutorado) em Distúrbios da Comunicação Humana, Fonoaudiologia Santa Maria, Rio Grande do Sul, Brasil. Universidade Federal de Santa Maria UFSM, Departamento de Fonoaudiologia e Programa de Pós-graduação em Distúrbios da Comunicação Humana, Santa Maria, Rio Grande do Sul, Brasil.

This work was performed in the Phonoaudiology Course, at the Federal University of de Santa Maria - UFSM Santa Maria Rio Grande do Sul, Brasil.

Conflict of interests: Nonexistent

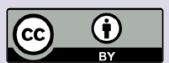

Received on: October 1, 2018

Approved on: August 14, 2019

Corresponding address:

Taissane Rodrigues Sanguebuche Avenida Independência, $n^{0} 820$, apartamento 903, Bairro Passo da Areia CEP: 97010-240 - Santa Maria, Rio Grande do Sul, Brasil

E-mail: taissane.sanguebuche@outlook. com

\section{ABSTRACT}

Purpose: to generate reference values for different behavioral central auditory processing (CAP) tests in normally hearing adults, with age stratification, as well as to compare the results, according to the presence or absence of CAP disorder (CAPD).

Methods: the study sample consisted of 94 adults with normal auditory thresholds, with at least 11 years of schooling, who were divided into two groups, according to the performance in the Dichotic Sentences Identification Test (DSI), Masking Level Difference (MLD), Random Gap Detection Test (RGDT), Adapted Time-Compressed Speech (ATCS) and Duration and Frequency Pattern Tests (DPT/FPT). The 64 subjects who presented normality in all the tests formed the G1 group and the 30 subjects who presented alteration in at least one of them, originated the G2 group. To accomplish the analysis it was used the Mann-Whitney $U$ Test. In all analyzes, the significance level was $5 \%(p \leq 0.05)$.

Results: the sum of the two standard deviations for the mean performance of $\mathrm{G} 1$ yielded reference values for the different tests addressed. When G1 and G2 groups were compared, G1 presented better results, this being significant in the DSI (left ear), MLD, RGDT, DPT and FPT tests, for the group aged between 18 and 29 years and, DSI (right ear), RGDT and ATCS (right ear), for the group from 30 to 58 years.

Conclusion: it was possible to generate reference values for different behavioral tests of CAP in normally hearing adults, as well as to verify a better performance for the group with no CAPD.

Keywords: Hearing; Hearing Tests; Auditory Perception; Auditory Perceptual Disorders 


\section{INTRODUCTION}

The main means of interaction that an individual has with the world is communication, and in order to have an effective communication, the integrity of hearing is a requisite, at both the peripheral and central levels ${ }^{1}$. Therefore, the fact that an individual has normal audibility for pure tones and for speech intelligibility test does not imply that he is able to process and interpret auditory information in general, considering all the variables that can influence this complex comprehension process ${ }^{2}$.

For this, the assessment of central auditory processing (CAP) is most suitable choice, which is performed through behavioral tests that aim to assess the individual's auditory performance by simulating situations faced in daily life. A good performance in these situations may reflect the integrity of the auditory physiological mechanisms, which are fundamental in the acoustic processing of information, in speech perception, in learning and in language comprehension ${ }^{3,4}$.

Behavioral tests usually reveal functional deficits in the CAP and they are reference when it comes to diagnosis and rehabilitation in this area. However, it is difficult to describe which test should be applied in each case, which standard of normality should be considered, or even how many tests are necessary for an accurate diagnosis in the clinical evaluation ${ }^{5}$. This is due to the particularity of each patient, be it in relation to age group ${ }^{6,7}$, education level ${ }^{8}$ or audiometric configuration?.

As a result, describing a battery of behavioral tests that is efficient in detecting central changes has become increasingly important lately. This study took into account the individual aspects of the subjects, who were divided by age group and had at least a minimum level of education. Also, only subjects with peripheral auditory normality were accepted. This selectivity is crucial in view of the fact that, apparently, it is not feasible to expect a child to present similar results to an adult or even people at the same age but from different nationalities to have the same responses, considering the maturation of the central nervous system and the experiences lived in the life course ${ }^{10}$. Therefore, the justification for this study lies in the search for more specific answers for the national adult population, with good education and a representative number of individuals.

Thus, the objective of this study was to generate reference values for different CAP behavioral tests in normally hearing adults, with stratification of age group and satisfactory level of education, as well as to compare the results, according to the variable "presence or absence" of hearing disorder CAP.

\section{METHODS}

This study was approved by the Research Ethics Committee of the Federal University of Santa Maria - UFSM, under number 80732817.0.0000.5346 and has a prospective, quantitative and transversal nature. All assessments were performed at the Audiology Outpatient Clinic of the University Hospital in Santa Maria, RS, Brazil. Only individuals who agreed on voluntary participation and signed the Free and Informed Consent Term (ICF) were accepted. This term contained information about the performed procedures, risks, benefits and confidentiality of the research data, following all ethical principles, as Resolution 466/12 of the National Health Council.

\section{Eligibility Criteria}

To compose the sample, the following eligibility criteria were considered: subjects aged between 18 and 59 years old with hearing thresholds within normal limits, that is, up to $25 \mathrm{~dB} \mathrm{HL}$ at frequencies 250 to 8000 $\mathrm{Hz}^{11}$, type "A" tympanometric curve ${ }^{12}$, present contralateral acoustic reflexes bilaterally, Brazilian Portuguese as mother language, right hand preference ${ }^{13}$, complete secondary education, according to the methodological model of the Brazilian demographic census conducted by IBGE in 2000. In addition, absence of evident neurological and / or psychological impairment and retrocochlear alteration, assessed through the Brainstem Auditory Evoked Potential with click stimulus (click BAEP).

\section{Casuistry}

Thus, the sample consisted, for convenience, of 94 subjects, 42 of whom were male (44.7\%) and 52 were female (55.3\%), aged between 18 and 58 years old and average age of 28.04 years. Of these 94 subjects, 64 belonged to the G1 group and 30 to the G2 group. This distribution was made according to the performance in the CAP behavioral tests: the subjects who had satisfactory performance in all tests formed $\mathrm{G} 1$, while the subjects who had alterations in one or more tests formed G2. The distribution of the groups was carried out according to the concept of CAPD proposed by $\mathrm{ASHA}^{14}$, that is, changes in one or more hearing skills. 
In order to infer reference values, it is necessary to use clean data, that is, a sample without any alteration and, preferably, with fractionation of the age group, considering the maturation of the central nervous system. Therefore, when the term reference value is used in this work, the values found in the G1 group (64 subjects) are the ones to consider, by stratification of age group: 18 to 29 years old and 30 to 58 years old.

\begin{tabular}{|c|c|c|c|}
\hline Groups & Age group & Males $\mathbf{n}(\%)$ & Females $\mathbf{n}(\%)$ \\
\hline \multirow{2}{*}{ G1 } & $18-29$ years old & $25(39.02 \%)$ & $26(40.64 \%)$ \\
\cline { 2 - 4 } & $30-58$ years old & $7(10.95 \%)$ & $6(9.39 \%)$ \\
\hline \multirow{2}{*}{ G2 } & $18-29$ years old & $3(10 \%)$ & $12(40 \%)$ \\
\cline { 2 - 4 } & $30-58$ years old & $7(23.3 \%)$ & $8(26.7 \%)$ \\
\hline
\end{tabular}

Caption: $\mathrm{n}=$ individuals number; $\%=$ individuals percentage; $\mathrm{G} 1=$ normality in all the central auditory processing tests; $\mathrm{G} 2$ = alteration in, at least, one central auditory processing test

Figure 1. Distribution of G1 and G2 groups, according to age groups and gender

G1 $(n=64)$ was composed of 51 subjects aged between 18 and 29 years old (mean of 22.63) and 13 subjects aged 30 to 58 years (mean of 38.54 ). G2 $(n=30)$, on the other hand, consisted of 15 subjects aged between 18 and 29 years old (mean of 22.93) and 15 subjects aged 30 to 58 years old (mean of 42.47). Other studies have already been carried out with the aim of generating reference values with considerably small samples ${ }^{15,16}$. It is important to highlight that the age group from 30 to 58 years old presents a sample of less relevance when compared to those from 18 to 29 years old. However, we decided to perform the stratification of age group, since the auditory system works differently from the third decade of life onwards ${ }^{17}$.

\section{General procedures}

All subjects were submitted to an Audiological Anamnesis, in order to collect information about previous diseases, issues related to communication and family history of hearing diseases. Also, they were submitted to the reduced version of the Edinburgh Manual Dominance test ${ }^{13}$, in order to obtain information about manual preference in different situations of everyday life. A Mikatos clinical otoscope was used for visual inspection of the external auditory canal. The behavioral audiological evaluation was performed in a booth with acoustic treatment, with pure tone audiometry, logoaudiometry and CAP tests performed on the Interacoustics audiometer, model AD229e, using supra aural headphones model TDH 39. The Acoustic Immittance Measurements were performed on the tympanometer model AT235 from the brand Interacoustics.

In addition, the BAEP click was performed on the Smart EP equipment from the Intelligent Hearing Systems (IHS) brand. The stimulus was performed through insertion earphones in both right and left ears, at a speed of 27.7 stimuli per second, with 2048 sweeps at $80 \mathrm{~dB}$ NA intensity, with a 12 ms recording window, 100-3000 filters, $\mathrm{Hz}$ passes high and low respectively, repetition rate $100.0 \mathrm{~K}$, stimulus duration $100 \mu \mathrm{sec}$, rarefied polarity. Only subjects with click BAEP within normality were included in the research, that is, when the absolute latencies of waves I, III and V and interpeak intervals I-III, III-V and IV presented values (ms) within the expected for the equipment: $I=1.66 / S D=0.101$; $\mathrm{III}=3.87 / \mathrm{SD}=0.146 ; \mathrm{V}=5.68 / \mathrm{SD}=0.119 ; \mathrm{I}-\mathrm{III}=$ $2.21 / \mathrm{SD}=0.142 ; \mathrm{III}-\mathrm{V}=1.81 / \mathrm{SD}=0.105 ; \mathrm{I}-\mathrm{V}=4.02$ $/ \mathrm{SD}=0.131$, using two standard deviations ${ }^{18}$.

\section{Specific Procedures}

As a CAP battery, six tests were applied in the following order: Dichotic Sentence Identification Test (SDI), Masking Level Difference (MLD), Frequency Pattern Test (FPT), Adapted Time-Compressed Speech (ATCS), Randon Gap Detection Test (RGDT) and Duration Pattern Test (DPT). As the cutoff point for normality or alteration, the closest values found in the literature were considered, even if they came from an international population, without stratification of age range or even with a small sample size.

The SDI test was applied at an intensity of $50 \mathrm{~dB}$ NS, in order to assess the auditory ability of figure-ground 
for verbal sounds ${ }^{19}$. Although the test started with training and then the binaural integration step was performed, only the ladder was considered in the analysis of this study. In these two moments, two sentences were simultaneously presented, one in each ear, and the subject pointed out the two phrases heard, on a chart, which remained fixed in front of them. As criterion of normality, the following values proposed by age group ${ }^{20}$ were used: from 13 to 19 years old: $80 \%$ of correct answers in the RE and $70 \%$ in the LE; from 20 to 29 years old: $80 \%$ of correct answers in the RE and $60 \%$ in the LE; from 30 to 49 years: $70 \%$ of correct answers in the RE and $60 \%$ in the LE. Unlike the other tests, the objective of seeking new reference values was to modify the data analysis, considering that the author used the $5^{\text {th }}$ percentile measures for this, and may have generated lower values.

The MLD test consists of determining the auditory threshold by a pure pulsatile tone of $500 \mathrm{~Hz}$, in the presence of a masking noise in two different conditions: pure noise and tone presented in phase for both ears; and pure tone presented in phase in both ears, with inverted phase noise in one ear. This test was also performed at $50 \mathrm{~dB} N$, in the binaural condition and the subjects were instructed to say "yes" when they heard the pure tone and "no" when they heard only the noise. The result was obtained by subtracting the threshold between the two conditions. MLD was considered normal in the presence of threshold differences greater than or equal to $10 \mathrm{~dB}$ between the signal / noise conditions verified ${ }^{21}$.

The ATCS test was used in this research, in order to assess the ability of auditory closure, in a monoaural way. In this test, the subject listened to a list composed of 25 dissyllable words and repeated them as he understood. To the same test $40 \mathrm{~dB}$ NS was applied, and the average values found for the age group 18 to 33 years old were used as a reference in the adapted test, that is, $92 \%$ of correct answers ${ }^{22}$. Despite presenting such a percentage, the authors of the instrument suggested that further studies should be carried out in order to generate standards for other ages with a representative sample.

RGDT is composed of sequences of pure paired tones, in the frequencies of 500, 1000, 2000 and 4000 $\mathrm{Hz}$. The intervals between the tones vary from zero to $40 \mathrm{~ms}$ in random order. The test was performed at $50 \mathrm{~dB} N \mathrm{NS}$, in the binaural condition and the subjects were instructed to respond verbally if they heard one or two tones. The training band and the test bands were applied, in order to verify the smallest interval after which the individual started to always identify two tones. The analysis took place by means of the average of the four test frequencies and results of $10 \mathrm{~ms}$ or less were considered normal for the age group between 20 and 40 years old and equal to or less than $15 \mathrm{~ms}$ for the age group between 41 and 59 years ${ }^{16}$.

To assess the auditory ability of temporal ordering, the Auditec ${ }^{\circledR}$ Frequency and Duration Standard tests (FPT and DPT) were applied. The FPT is made up of sequences composed of three tones, with two of the tones presented being of one frequency while the third is presented at a different frequency. The subject named the sequence he heard, using the answers "thin" and "thick". The test was applied in the binaural condition, at an intensity of $50 \mathrm{~dB} \mathrm{NS}$, and the normality pattern proposed for adults was used with results equal to or above $90 \%$ of correct answers ${ }^{23}$. In the DPT, the subject named the sequence he heard, using the answers "short" and "long". The test was also applied in the binaural condition, at an intensity of $50 \mathrm{~dB} N S$, and as a standard of normality, results equal to or above $67 \%$ of correct answers, proposed for adults ${ }^{23}$.

\section{Data analysis}

For data analysis, firstly a description was performed, with values of mean, standard deviation (SD), minimum, maximum and confidence interval. Subsequently, the non-parametric test of comparison between Mann-Whitney $U$ variables was used. In all analyzes, the significance level was $5 \%(p \leq 0.05)$.

It is noteworthy that to generate the reference values, the average value found for the G1 group was used and the value of two SDs was added upwards and downwards, considering the probable variability from one subject to the other.

\section{RESULTS}

In Table 1, it is possible to observe the description of the reference values, explained through the findings of $\mathrm{G} 1$, as well as the comparison between groups $\mathrm{G} 1$ and G2, for all applied CAP behavioral tests, for the age group of 18 to 29 years old. A statistically significant difference is perceived in most of the data shown in the table, which indicates a higher score in the normal group. The exception is found in the DSI test (right ear) and in the ATCS test (both ears), in which the values remained quite similar for both groups. 
Table 1. Description of the reference values for the central auditory processing behavioral tests and comparison between $\mathrm{G} 1$ and $\mathrm{G} 2$ groups, according to the age group of 18 to 29 years old

\begin{tabular}{|c|c|c|c|c|c|c|c|c|}
\hline CAP Tests & Groups & $\mathbf{N}$ & Average & SD & Min & Max & IC & P-value \\
\hline \multirow{2}{*}{ DSI RE (\%) } & G1 & 51 & 96 & 8.0 & 70 & 100 & 2.2 & \multirow{2}{*}{0.699} \\
\hline & G2 & 15 & 94.7 & 6.3 & 80 & 100 & 3.2 & \\
\hline \multirow{2}{*}{ DSI LE (\%) } & G1 & 51 & 94.3 & 7.0 & 80 & 100 & 1.9 & \multirow{2}{*}{$0.021^{*}$} \\
\hline & G2 & 15 & 88 & 10.1 & 70 & 100 & 5.1 & \\
\hline \multirow{2}{*}{ MLD (dB) } & G1 & 51 & 14 & 2.3 & 10 & 20 & 0.6 & \multirow{2}{*}{$0.007^{*}$} \\
\hline & G2 & 15 & 10.9 & 4.3 & 4 & 18 & 2.2 & \\
\hline \multirow{2}{*}{ RGDT (ms) } & G1 & 51 & 4.79 & 2.36 & 2 & 10 & 0.65 & \multirow{2}{*}{$0.028^{*}$} \\
\hline & G2 & 15 & 9.52 & 9.61 & 2 & 40 & 4.86 & \\
\hline \multirow{2}{*}{ ATCS RE (\%) } & G1 & 51 & 92.1 & 5.5 & 80 & 100 & 1.5 & \multirow{2}{*}{0.317} \\
\hline & G2 & 15 & 87.7 & 10.6 & 64 & 96 & 5.4 & \\
\hline \multirow{2}{*}{ ATCS LE (\%) } & G1 & 51 & 94 & 5.0 & 84 & 100 & 1.4 & \multirow{2}{*}{0.132} \\
\hline & G2 & 15 & 90.1 & 8.7 & 72 & 100 & 4.4 & \\
\hline \multirow{2}{*}{ DPT (\%) } & G1 & 51 & 91.9 & 8.4 & 70 & 100 & 2.3 & \multirow{2}{*}{$0.022^{*}$} \\
\hline & G2 & 15 & 80.6 & 20.4 & 23 & 100 & 10.3 & \\
\hline \multirow{2}{*}{ FPT (\%) } & G1 & 51 & 97.2 & 4.8 & 77 & 100 & 1.3 & \multirow{2}{*}{$0.005^{*}$} \\
\hline & G2 & 15 & 84.9 & 16.8 & 53 & 100 & 8.5 & \\
\hline
\end{tabular}

Statistical test: U de Mann-Whitney (p-value $\leq 0,05$ )

Caption: CAP = Central Auditory Processing; $\mathrm{N}=$ Individuals Number; $\mathrm{SD}=$ Standard Deviation; Min = minimum; $\mathrm{Max}=$ maximum; $\mathrm{Cl}=\mathrm{Confidence} \mathrm{Interval;} \mathrm{RE}$ $=$ Right Ear; LE = Left Ear; DSI = Dichotic Sentence Identification Test; MLD = Masking Level Difference; RGDT = Random Gap Detection Test; Adapted TimeCompressed Speech (ATCS); DPT = Duration Pattern Test; FPT = Frequency Pattern Test; $\mathrm{dB}=$ decibels; $\mathrm{ms}=$ milliseconds; $\%=$ percent; $\mathrm{G1}=$ normality in all behavioral tests; $\mathrm{G} 2$ = alteration in at least one behavioral test; * $=$ significant $\mathrm{p}$-value.

Table 2 shows the description of reference values (G1), as well as the comparison between groups $\mathrm{G} 1$ and G2 for all applied CAP behavioral tests; however, for the age range from 30 to 58 years old. In this case, there is a significant difference in the DSI (left ear), RGDT and ATCS (right ear) test, with better performance in the normal group.

Table 2. Description of reference values for behavioral tests of central auditory processing and comparison between groups G1 and G2 in the age group from 30 to 58 years old

\begin{tabular}{lcccccccc}
\hline CAP Tests & Groups & N & $\begin{array}{c}\text { Mean } \\
\text { average }\end{array}$ & SD & Min & Max & IC & P-value \\
\hline DSI RE (\%) & G1 & 13 & 93.1 & 10.3 & 70 & 100 & 5.6 & 0.487 \\
& G2 & 15 & 84.7 & 21.9 & 20 & 100 & 11.1 & \\
DSI LE (\%) & G1 & 13 & 90 & 10.0 & 70 & 100 & 5.4 & $0.042^{*}$ \\
& G2 & 15 & 79.3 & 16.8 & 40 & 100 & 8.5 & \\
MLD (dB) & G1 & 13 & 13.1 & 2.4 & 10 & 18 & 1.3 & 0.260 \\
& G2 & 15 & 11.6 & 3.6 & 6 & 18 & 1.8 & \\
RGDT (ms) & G1 & 13 & 5.58 & 2.37 & 2.75 & 10 & 1.29 & $0.009^{*}$ \\
& G2 & 15 & 10.08 & 4.62 & 2 & 17.5 & 2.34 & \\
ATCS RE (\%) & G1 & 13 & 88.9 & 3.7 & 80 & 92 & 2.0 & $0.042^{*}$ \\
ATCS LE (\%) & G1 & 15 & 81.9 & 11.1 & 56 & 96 & 5.6 & \\
& G2 & 13 & 92.6 & 3.9 & 84 & 96 & 2.1 & 0.088 \\
DPT (\%) & G1 & 15 & 84.5 & 13.0 & 60 & 100 & 6.6 & \\
& G2 & 15 & 89 & 8.1 & 70 & 100 & 4.4 & 0.082 \\
FPT (\%) & G1 & 13 & 76.9 & 20.0 & 27 & 100 & 10.1 & \\
\hline
\end{tabular}

Caption: $\mathrm{CAP}=$ central auditory processing; $\mathrm{N}=$ Individuals Number; $\mathrm{SD}=$ standard deviation; Min = minimum; $\mathrm{Max}=$ maximum; $\mathrm{Cl}=$ confidence interval; $\mathrm{RE}$ = right ear; LE = left ear; DSI = Dichotic Sentence Identification Test; MLD = Masking Level Difference; RGDT = Random Gap Detection Test; Adapted Time-

Compressed Speech (ATCS) DPT = Duration Pattern Test; FPT = Frequency Pattern Test; $\mathrm{dB}=$ decibels; $\mathrm{ms}=$ milliseconds; $\%=$ percent; $\mathrm{G} 1=$ normality in all behavioral tests; $\mathrm{G} 2$ = alteration in at least one behavioral test; ${ }^{*}=$ significant $\mathrm{p}$-value. 


\section{DISCUSSION}

The discussion of the results shown in Tables 1 and 2 will be carried out jointly, for a better comprehension of the data analysis. Initially, in the DSI test, which is the binaural integration stage, the average values found were very similar to those from a pioneering study whose objective was to standardize the test in normally hearing adults, in terms of age group ${ }^{24}$. However, the author considered the 5th percentile's values to be normal, concerning the DSI, which seem to be inferior, in relation to the average in both studies. Studies which compared the test already adapted to Brazilian Portuguese were not found.

In the comparative analysis, G2 presented inferior results in both analyzed age groups when compared to G1, with statistical significance only in the left ear (Tables 1 and 2). These results highlight the importance of including a dichotic test on the CAP battery, considering that the task of binaural integration, constantly carried out in people's daily lives - in situations such as the classroom, group conversations and in the family environments - is limited in individuals with CAPD ${ }^{25}$. Usually, the activity of focusing the attention on what is important and ignoring what does not matter at the moment is a simple and ordinary activity. This action raises the hypothesis that individuals, with complaints and deviations related to the CAP, present a dysfunction in the inter-hemispheric transmission. This hypothesis is strengthened when a noticeable disadvantage on the left ear in relation to the G2 is observed. However, this fact is usually expected in children and elderly populations and it is the result of the longer transmission time from the non-dominant hemisphere for linguistic stimuli, to the dominant hemisphere for this type of stimulation, through the corpus callosum. Therefore, even in the adult population, the present study demonstrates that the CAPD group presented greater difficulty in this transmission than the normal group does.

In relation to the MLD test, by observing the average values found in Tables 1 and 2, similar results, even with the increase of age, with $14 \mathrm{~dB}$ for the youngest group and $13.1 \mathrm{~dB}$ for the group between 30 and 58 years old, were noted. A study which is usually used as reference ${ }^{21}$ carried out a series of experiments with normally hearing young adults, trying to develop a simple application protocol for MLD by using a $500 \mathrm{~Hz}$ pulsatile tone. Throughout the experiments, the authors observed that $95 \%$ of the individuals presented a result which was equal to or greater than $10 \mathrm{~dB}$. Another research ${ }^{26}$ which tried to generate the reference value for MLD in young female adults, who do not hold a four-year degree, found out a similar average value: $10.83 \mathrm{~dB}$. However, it is important to mention that a well-known study, also carried out with normally hearing adults $^{27}$, which found results greater than or equal to 6 $\mathrm{dB}$ as normal for the test. The results aforementioned diverge from each other and they are considerably lower than those found in the present research, demonstrating that not always the MLD have a constant in terms of responses, even in similar populations.

Also, the comparison in relation to the performance among the groups in the MLD test showed a lower result for G2, with a statistically significant difference in the younger group (Table 1). The intensity averages found for $\mathrm{G} 1$, in the age group of 18 to 29 and of 30 to 58 , demonstrated that normal individuals are able to keep their attention with a stimulus that is, respectively, up to $14 \mathrm{~dB}$ and $13.1 \mathrm{~dB}$ below a competitive noise. On the other hand, individuals with CAPD need to reduce the noise in a competition to be able to focus their attention. This superiority in the G1 group was already expected due to the psychoacoustic phenomenon called masking release, that is, when individuals with normal brainstem function are supposed to obtain an aptitude in detecting a signal presented in the presence of a competitive bilateral noise, having a better performance in the test ${ }^{1}$.

Concerning the RGDT test, when we compare the average values obtained in the current research to a study ${ }^{16}$ which aimed at generating normality for the hearing ability of temporal resolution in audiologically normal individuals, aged from 20 to 60 years old, better values are found. Such study divided the age group into four groups composed by 10 individuals each, namely: from 20 to 30 years old; from 31 to 40 years old; from 41 to 50 years old; and from 51 to 60 years old; as average values $6 \mathrm{~ms}, 8 \mathrm{~ms}, 8.8 \mathrm{~ms}$ and $10.1 \mathrm{~ms}$, respectively. However, it is important to highlight that the normality criterion described in this study was not carried out only with the average age, but by but adding it to the IC. Therefore, the authors considered values equal to or less than $10 \mathrm{~ms}$ for ages between 20 and 40 years old and values between 10 and $15 \mathrm{~ms}$ for ages between 41 and 60 years old as normal. The average values in both current and aforementioned studies are different. So, this result may be attributed to the to the sample composition mode. In other words, such study considered as criterion of inclusion to generate this normality, to present $95 \%$ or more of correct answers in the Dichotic Listening Test, which aimed at evaluating 
the figure-ground ability for verbal sounds while the current research has required normality in a complete battery of CAP tests.

Also, in relation to the RGDT test, when comparing the performance between $\mathrm{G}_{1}$ and $\mathrm{G} 2$, it is possible to observe a statistically significance difference in both analyzed age groups (Tables 1 and 2). Such results show that normal individuals are able to perceive minimum intervals of silence during the connected speech, bringing a better comprehension of the speech when compared to the altered group. It is important to bring data related to the temporal processing in the adult population, since the degradation of these aspects in aging is strongly emphasized ${ }^{28}$. However, such alteration may not relate to structural aspects only, but also functional aspects of the central auditory nervous system, causing difficulties for children and adults to identify minor acoustic variations of speech and, consequently, difficulty in producing correctly the verbal sounds or in interpreting the heard message. A study ${ }^{29}$, that adopted a similar methodology to the one adopted in the present research, but with younger age groups, from 5 to 25 years old, also found a strong correlation between individuals with CAPD and a worse performance in the RGDT test. Thus, the authors suggested the insertion of it in the battery of tests proposed by Bellis ${ }^{10}$, in the category of temporal aspects.

In the ATCS test, it is possible to observe an increase in terms of correct answers in the left ear when compared to the right one. This result could have brought a question related to the common advantage of the right ear for linguistic stimuli. However, perceptual asymmetry is not really expected in monoaural tests due to the participation of both contra and ipsilateral pathways of the auditory nervous system, neutralizing the advantage of the right ear for this type of stimulus $^{11}$. Therefore, the superiority of the left ear, in the current research, is probably attributed to the testing effect. This fact occurs because the same list of words, although in a different order, is applied on both ears, starting from the right one. A study ${ }^{30}$, which aimed at evaluating the ability of auditory closure by using another test "Speech in Noise", also verified a difference between the ears and a better performance in the left one. This fact is justified by the learning effect, since the same list was applied to both ears and the left one was the last to be tested. Also, the authors that adapted the ATCS instrument for the reduced version ${ }^{22}$, applied it in 73 individuals aged between 16 and 30 years old and obtained as average values: $92.11 \%$ for the right ear and $92.66 \%$ for the left one without differences between the ears. It is important to highlight that for this adaptation, no new words were created, but 25 were selected from a phonetic balance, among the lexical items already existing in the original instrument. Therefore, the use of the reduced version in the evaluation of the ability of auditory closure is indicated due to the better applicability and preservation of the original instrument's characteristics.

When the performance of $\mathrm{G} 1$ and $\mathrm{G} 2$ groups is compared, a higher percentage of correct answers for the normal group (G1) is observed, but with a statistical significance only in the right ear of the group of 30 to 58 years old (Table 2). This greater difficulty in the group with CAPD was already expected, in view of the main complaint these days: an everyday environment which is rarely ideal for conversation. When extrinsic factors - such as the knowledge of the subject and of the phonemic aspects of speech; familiarity with the vocabulary and with the language rules; among others - that help the auditory closure are known by the listener, minimal effort is required to follow the conversation. On the other hand, if one or more of these factors are absent, it is essential to count on the intrinsic ability of the central auditory nervous system in order to be able to interpret what is said ${ }^{31}$. Therefore, any complication that reduces the extrinsic redundancy of the auditory signal may interfere in the individual's capacity to achieve the auditory closure, a very common fact in clinical practice.

Still observing the reference values in Tables 1 and 2 , the DPT also presented similar averages, even with the increase of age. The reference value proposed by Auditec ${ }^{\circledR}$ is $67 \%$ of correct answers, which seems to be a value apparently simple to be achieved because it allows a considerable margin of errors. On the other hand, a national study ${ }^{32}$ evaluated 20 adults, divided into two age groups, and obtained as average correct answers: $80.6 \%$ for the age group between 35 and 45 years old and $74.3 \%$ for 46 to 55 years old. The methodology of this work does not explicit which version of the test was used. However, from the description provided, we believe Auditec ${ }^{\circledR}$ version was used as well. Such values are considerably higher than the ones previously described, but they are still lower than those found in the present research. The educational level is not supposed to be a hypothesis because the study also proposes a good level for those individuals. However, no CAP tracking test was applied, 
besides the Mini Mental State Examination (MMSE), which aims at evaluate the cognitive function. These values may be influenced by individuals with phonological alteration. Furthermore, the authors themselves suggest continuing the study, with the objective of increasing the sample number and generating results with stronger reliability.

The TDP, as well as the TPH, presents normality, already described by Auditec ${ }^{\circledR}$, that corresponds to $90 \%$ or more of right answers. This value is very similar to the one found in the current research. However, at this time, the aforementioned study ${ }^{32}$ presented lower values compared to the others, being $69.5 \%$ for 35 to 45 years old and $67.3 \%$ for 46 to 55 years old. It is noteworthy again that there was no CAP tracking test in this study, so the values may be influenced by altered individuals. An international study ${ }^{33}$, aimed at generating reference values for this test in a group of 76 normally hearing individuals, with ages between 18 and 54 years old and with monoaural application, obtained as average values: $81.4 \%$ of correct answers for the right ear and $83.6 \%$ for the left one. These values were also lower than those found in the current research. This fact may be associated to the inclusion criteria of such study, which took into consideration only the patient's complaints and references, without applying a protocol or a questionnaire to quantify the real results.

Finally, it is also possible to observe the difference in the performance between the G1 and G2 groups in relation to the DPT and FPT tests, with significance only in the young adult's age group (Table 1). Much evidence suggests that the temporal processing abilities are the CAP base. The argument which supports this proposition is that many characteristics of the auditory information are, somehow, influenced by time ${ }^{34}$. Therefore, the worst performance in the group with CAPD (G2) is related to the greater difficulty in recognizing the acoustic characteristics of speech, such as prosodic details, accent and rhythm, a very common complaint in individuals who present such disorder. Both tests were satisfactory in finding alterations in the auditory ability of temporal ordering, which confirms their widespread acceptance in the batteries of behavioral tests.

In order to conclude the discussion of Tables 1 and 2 , we highlight the average values herein described were higher than those found in the literature in general. This fact is probably related to the group without complaints and alterations, as well as with minimum educational level of 11 years, which was used to generate such reference values. However, ASHA $^{14}$ suggests that up to two SD be used in the CAP tests, in view of the variability of responses that may occur from one individual to another. Besides, an important statistical analysis, called Gauss Distribution, which provides data on the sample representativeness, is very important. In this case, using only one SD would represent $68.27 \%$ of the population. On the other hand, using two SD would represent $95.45 \%$ of it. Thus, the current research suggests the adoption of two SD in relation to the average, always taking into consideration the individual's medical history and trying to find a greater representativeness and fewer misdiagnosis and inadequate conduct.

For easier viewing, Figure 2 presents the average values, the SD values, the reference values that foresee the use of two SD and, at last, the whole values to be used in the audiological clinic for all CAP tests, according to age group. It is important to highlight that such values come from G1, the group without CAPD. 


\begin{tabular}{|c|c|c|c|c|c|c|}
\hline & $\begin{array}{c}\text { Mean + SD } \\
\mathbf{1 8 - 2 9} \text { years }\end{array}$ & $\begin{array}{c}\text { Reference value } \\
\mathbf{1 8 - 2 9} \text { years }\end{array}$ & $\begin{array}{c}\text { Final value } \\
\mathbf{1 8 - 2 9} \text { years }\end{array}$ & $\begin{array}{c}\text { Mean + SD } \\
\mathbf{3 0 - 5 8} \text { years }\end{array}$ & $\begin{array}{c}\text { Reference value } \\
\mathbf{3 0 - 5 8} \text { years }\end{array}$ & $\begin{array}{c}\text { Final value } \\
\mathbf{3 0 - 5 8} \text { years }\end{array}$ \\
\hline DSI RE (\%) & $96-8.0$ & 80 & $\geq 80$ & $93.1-10.3$ & 72.5 & $\geq 70$ \\
\hline DSI LE (\%) & $94.3-7.0$ & 80.3 & $\geq 80$ & $90-10.0$ & 70 & $\geq 70$ \\
\hline MLD (dB) & $14-2.3$ & 9.4 & $\geq 8$ & $13.1-2.4$ & 8.3 & $\geq 8$ \\
\hline RGDT (ms) & $4.79-2.36$ & 9.51 & $\leq 9.51$ & $5.58-2.37$ & 10.32 & $\leq 10.32$ \\
\hline ATCS RE (\%) & $92.1-5.5$ & 81.1 & $\geq 80$ & $88.9-3.7$ & 81.5 & $\geq 80$ \\
\hline ATCS LE (\%) & $94-5.0$ & 84 & $\geq 84$ & $92.6-3.9$ & 84.8 & $\geq 84$ \\
\hline DPT (\%) & $91.9-8.4$ & 75.1 & $\geq 73.3$ & $89-8.1$ & 72.8 & $\geq 70$ \\
\hline FPT (\%) & $97.2-4.8$ & 87.6 & $\geq 86.6$ & $96.6-4.9$ & 86.8 & $\geq 86.6$ \\
\hline
\end{tabular}

Caption: SD = standard deviation; RE = right ear; LE = left ear; DSI = Dichotic Sentence Identification Test; MLD = Masking Level Difference; RGDT = Random Gap Detection Test; Adapted Time-Compressed Speech (ATCS); DPT = Duration Pattern Test; FPT = Frequency Pattern Test; $\mathrm{dB}=$ decibels; $\mathrm{ms}=$ milliseconds; $\%=$ percent

Figure 2. average values, standard deviation and reference for the different behavioral tests of central auditory processing in the age groups from 18 to 29 years old and from 30 to 58 years old

Finally, we suggest that further studies be conducted by using this variability provided by the SD, since it is importance to update the audiological diagnosis and to ensure the correct conduct for each case.

\section{CONCLUSION}

It was possible to generate reference values for the different CAP behavioral tests, here presented, in an adult normally hearing population, with stratification of age group and satisfactory educational level. When comparing the results of such tests between both groups - with presence and absence of CAPD - worse values for the altered groups were found.

\section{REFERENCES}

1. Frota S, Pereira LD. Processamento auditivo: estudo em crianças com distúrbios da leitura e da escrita. Rev Psicopedag. 2010;27(83):214-22.

2. Balen SA, Bretzke L, Mottecy CM, Liebel G, Boeno MRM, Gondim LMA. Resolução temporal de crianças: comparação entre audição normal, perda auditiva condutiva e distúrbio do processamento auditivo. Rev Bras Otorrinolaringol. 2009;75(1):123-9.

3. Henriques MO, Costa MJ. Reconhecimento de sentenças no ruído, em campo livre, em indivíduos com e sem perda auditiva. Rev. CEFAC. 2011;13(6):1040-7.

4. Correa BM, Rossi AG, Roggia B, Silva AMT. Análise das habilidades auditivas de crianças com respiração oral. Rev. CEFAC. 2011;13(4):668-75.
5. Alonso R, Schochat E. A eficácia do treinamento auditivo formal em crianças com transtorno de processamento auditivo (central): avaliação comportamental e eletrofisiológica. Braz J Otorhinolaryngol. 2009;75(5):726-32.

6. Buss LH, Rossi AG, Buss $\mathrm{CH}$, Oliveira RC. Performance in the auditory abilities of selective attention and hearing memory in a group of elderly with hearing aids: influence of hearing loss, age and gender. Rev. CEFAC. 2013;15(5):1065-72.

7. Tun PA, Williams VA, Small BJ, Hafter ER. The effects of aging on auditory processing and cognition. Am J Audiol. 2012;21(2):344-50.

8. Paulo DL, Yassuda MS. Queixas de memória de idosos e sua relação com escolaridade, desempenho cogntivo e sintomas de depressão e ansiedade. Rev Psiq Clin. 2010;37(1):23-6.

9. Nishihata R, Vieira MR, Pereira LD, Chiari BM. Processamento temporal, localização e fechamento auditivo em portadores de perda auditiva unilateral. Rev Soc Bras Fonoaudiol. 2012;17(3):266-73.

10. Bellis T. Differential diagnosis of (central) auditory processing disorder in older listeners. In: Musiek F, Chermak G (eds). Handbook of (Central) Auditory Processing Disorder. Auditory Neuroscience and Diagnosis San Diego Plural Publishing; 2007. p. 319-46.

11. Lloyd II, Kaplan H. 1978 apud MomensohnSantos TM, Russo ICP, Brunetto-Borgianni LM. Interpretação dos resultados da avaliação audiológica. In: Momensohn-Santos TM, Russo ICP (orgs). Prática da audiologia clínica. 6ed, São Paulo: Cortez, 2007. 
12. Jerger J, Jerger MS, Mauldin L. Studies in impedance audiometry: I. normal and sensorineural ears. Arch Otolaryngol. 1972;96(6):513-23.

13. Oldfield RC. The assessment and analysis of handedness: the Edinburg Inventory. Neuropsychologia. 1971;9(1):97-113.

14. ASHA: (Central) Auditory Processing Disorders The Role of the Audiologist [Position Statement], 2005 [acesso em ago 2012]. Disponível em: www. asha.org/policy.

15. Luz SV, Pereira LD. Teste de escuta dicótica utilizando dígitos em indivíduos idosos. Acta AWHO. 2000;19(4):180-4.

16. Braga BHC, Pereira LD, Dias KZ. Normality tests of temporal resolution: Random Gap Detection Test and Gaps-in-noise. Rev. CEFAC. 2015;17(3):836-46.

17. Pascual-Leone A, Amedi A, Fregni F, Merabet LB. The plastic human brain cortex. Annu Rev Neurosci. 2005;28:377-401.

18. Webster $R$. The auditory brainstem response (ABR): a normative study using the intelligent hearing system's smart evoked potential system [tese]. Towson, Maryland (USA): Towson University; 2017.

19. Andrade NA, Gil D, lório MCM. Elaboração da versão em Português Brasileiro do teste de identificação de sentenças dicóticas (DSI). Rev Soc Bras Fonoaudiol. 2010;15(4):540-5.

20. Andrade NA, Gil D, lório MCM. Valores de referência para o teste de identificação de sentenças dicóticas em português brasileiro segundo orelha e idade. Braz J Otorhinolaryngol. 2015;81(5)459-65.

21. Wilson $\mathrm{RH}$, Moncrieff DW, Townsend EA, Pillion $\mathrm{AL}$. Development of a $500-\mathrm{Hz}$ masking-level difference protocol for clinic use. J Am Acad Audiol. 2003;14(1):1-8.

22. Folgearini JS, Goulart LLA, Silva DD, Vellozo FF, Mezzomo CL, Garcia MV. Time-Compressed Speech Test: adaptation and validation. Rev. CEFAC. 2016;18(6):1294-301.

23. Auditec. Evaluation manual of pitch pattern sequence and duration pattern sequence. St Louis: Auditec; 1997.

24. Andrade AN. Teste de Identificação de Sentenças Dicóticas - DSI: desempenho em indivíduos audiologicamente normais [tese]. São Paulo (SP): Universidade Federal de São Paulo; 2009.

25. Rosa MRD, Ribas A, Marques JM. A relação entre o envelhecimento e a habilidade de escuta dicótica em indivíduos com mais de 50 anos. Rev Bras Geriatr Gerontol. 2009;12(3):331-43.
26. Mendes SC, Branco-Barreiro FCA, Frota S. Masking level difference: reference values in adults. Audiol. Commun. Res. 2017;22:e:1746.

27. Musiek FE. Frequency (pitch) and duration pattern tests. J Am Acad Audiol. 1994;5(4):265-8.

28. Queiroz DS, Branco-Barreiro FCA, MomensohnSantos TM. Desempenho do Teste de Detecção de Intervalo Aleatório- Random Gap Detection Teste (RGDT): estudo comparativo entre mulheres jovens e idosas. Rev Soc Bras Fonoaudiol. 2009;14(3):503-7.

29. Dias KZ, Jutras B, Acrani IO, Pereira LD. Random Gap Detection Test (RGDT) performance of individuals with central auditory processing disorders from 5 to 25 years of age. Int $\mathrm{J}$ Ped Otorhinolaryngol. 2012;76(2):174-8.

30. Oliveira JC, Murphy CFB, Schochat E. Auditory processing in children with dyslexia: electrophysiological and behavior evaluation. CoDAS. 2013;25(1):39-44.

31. Jacob LCB, Alvarenga KF, Zeigelboim BS. Avaliação audiológica do sistema nervoso auditivo central. Int Arch Otorhinolaryngol. 2000;4(4):144-51.

32. Miranda-Gonsalez EC, Alvarez LS. Os efeitos da idade no processamento auditivo temporal em adultos. Arq Med Hosp Fac Cienc Med. 2016;61(3):123-7.

33. Majak J, Zamysłowska-Szmtke E, Rajkowska E, Śliwińska-Kowalska M. Auditory temporal processing tests - normative data for polishspeaking adults. Med Pracy. 2015;66(2):145-52.

34. Samelli AG, Schochat E. The gaps-in-noise test: gap detection thresholds in normal-hearing young adults. Int J Audiol. 2008;47(5):238-45. 